\title{
OFICINAS DE REVISÃO DE MATEMÁTICA: UMA AÇÃO DO PIBID
}

\author{
Apresentação: Relato de Experiência \\ Itaiara Iza S. da Silva ${ }^{1}$; Juliana R. Ferreira ${ }^{2}$; Maria Teluzia da Cunha ${ }^{3}$; Francisco B. de Medeiros ${ }^{4}$
}

\section{Introdução}

Este trabalho surge a partir da experiência dos graduandos de Licenciatura em Matemática do Instituto Federal de Educação, Ciência e Tecnologia do Rio Grande do Norte (IFRN), na Escola Estadual Professor Francisco Ivo Cavalcanti, localizada na cidade do Natal-RN, como parte das atividades desenvolvidas no Programa Institucional de Bolsas de Iniciação à Docência (PIBID IFRN), subprojeto Matemática Campus Natal Central.

\section{Relato de Experiência}

O direito à educação gratuita e de qualidade é assegurada pela Lei no 9.394/96. Todavia, um dos dilemas da educação refere-se à permanência do estudante na escola. Para Tassoni (2011, p.64), "a busca pela permanência do aluno na escola está, entre outras coisas, intimamente relacionada ao sucesso escolar. Quanto mais capaz o aluno se sente, quanto mais inserido ele se encontra nas práticas escolares, aumenta-se a probabilidade de se manter na escola."

Na disciplina de Matemática, diversos fatores influenciam no baixo rendimento do estudante da educação básica. Nesse contexto, um dos objetivos do PIBID, de acordo com o disposto no Art. $4^{\circ}$ do seu Regulamento (instituído pela Portaria Nº96, de 18 de Julho de 2013), é;

\footnotetext{
Inserir os licenciandos no cotidiano de escolas da rede pública de educação, proporcionandolhes oportunidades de criação e participação em experiências metodológicas, tecnológicas e práticas docentes de caráter inovador e interdisciplinar que busquem a superação de problemas identificados no processo de ensino-aprendizagem.
}

Com intuito de contribuir para a aprendizagem do estudante da rede pública, o PIBID Matemática CNAT tem como uma de suas ações a realização de Oficinas de Revisão de Matemática, as quais surgem como uma proposta de construção de conhecimentos prévios de matemática, por acreditar que a obtenção desses conhecimentos facilita o processo de ensino-aprendizagem da respectiva disciplina e de disciplinas correlatadas, como Física e Química.

Com relação a metodologia, foi aplicado um teste diagnóstico, com estudantes do $1^{\mathrm{o}}$ ano do

\footnotetext{
${ }^{1}$ Graduanda de Licenciatura em Matemática, IFRN/CNAT, itaiara.iza@gmail.com

${ }^{2}$ Graduanda de Licenciatura em Matemática, IFRN/CNAT, julianarferreira@outlook.com

${ }^{3}$ Graduanda de Licenciatura em Matemática, IFRN/CNAT, teluzia2000@gmail.com

${ }^{4}$ Doutor em Matemática, IFRN/CNAT, francisco.medeiros@ifrn.edu.br
} 
Ensino Médio, matriculados no turno matutino da E. E. Prof. Francisco Ivo Cavalcanti, cobrindo os conteúdos estudados naquele ano. Percebeu-se que apesar da maioria dos alunos terem conhecimento do processo de solução das questões propostas no teste, eles ou não responderam corretamente ou não concluíram a solução iniciada. Verificamos, após avaliação das respostas, que o principal motivo foi a falta de domínio dos assuntos trabalhados em séries anteriores, como por exemplo: regras de sinais das operações básicas, expressões numéricas (potências e raízes), equações do $1^{\circ}$ grau, sistemas de equações do $1^{\circ}$ grau e equações do $2^{\circ}$ grau.

Depois de identificados os temas com os quais os estudantes apresentaram maior dificuldades, iniciou-se a construção e aplicação das Oficinas de Revisão de Matemática, com o intuito de superar as dificuldades por meio de atividades lúdicas capazes de dinamizar a teoria. Nas oficinas, foram desenvolvidas atividades como: a realização da Tabuada de Multiplicação com as Mãos; o jogo "O Caminho das Equações", para abordar as equações do $1^{\circ}$ e do $2^{\circ}$ graus; a utilização do Jogo da Memória para fixar as propriedades de potenciação e radiciação; e apresentação teatral sobre o crescimento exponencial.

Imagem 1: Atividades Desenvolvidas. Fonte: Própria

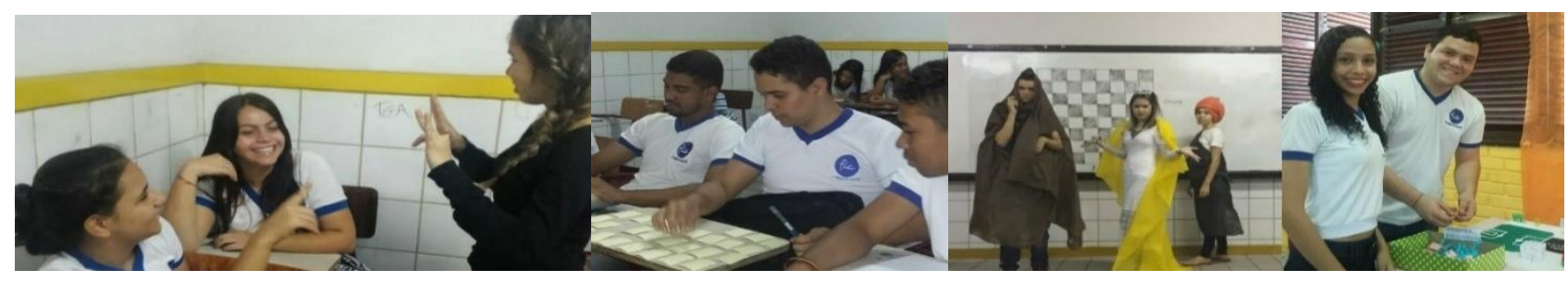

\section{Considerações}

Como resultado das Oficinas de Revisão de Matemática, houve o aumento tanto na quantidade de estudantes a cada encontro como no rendimento acadêmico dos participantes. Assim, verificou-se na prática que a construção de conhecimentos prévios de matemática foram capazes de estimular a autonomia desses estudantes e, por consequência, contribuir para o sucesso escolar nessa disciplina.

\section{Referências}

BRASIL. CAPES. Portaria n ${ }^{\circ} 096$ de 18 de julho de 2013. Regulamento do Programa Institucional de Bolsas de Iniciação à Docência. Disponível em: <www.capes.gov.br>. Acesso em: 25 set. 2017.

BRASIL. Presidência da República. Lei no 9.394 de 20 de dezembro de 1996. Estabelece as Diretrizes e Bases da Educação Nacional. Brasília, 1996. Disponível em <http://www.planalto.gov.br>. Acesso em: 20 set. 2017.

TASSONI, Elvira. As experiências de sucesso na aprendizagem e suas relações com a permanência na escola. Revista de Educação PUC-Campinas. Campinas, v.16, p. 57-64, jan. /jun. 2011. 